\title{
Strategy for Removing an Impacted Enterolith using Double-Balloon Enteroscopy in Crohn's Disease
}

\author{
Tatsuya Kikuchi ${ }^{1}$, Yasushi Yamasaki $^{1,2}$, Tsuyoshi Fujimoto ${ }^{1}$, Shouichi Tanaka ${ }^{1}$ \\ ${ }^{1}$ Department of Gastroenterology, Iwakuni Clinical Center, National Hospital Organization, Yamaguchi, Japan \\ ${ }^{2}$ Department of Gastroenterology, Okayama University Hospital, Okayama, Japan
}

Received: 03/01/2021

Accepted: 06/01/2021

Published: 28/01/2021

How to cite this article: Kikuchi T, Yamasaki Y, Fujimoto T, Tanaka S. Strategy for removing an impacted enterolith using double-balloon enteroscopy in Chron's disease. EJCRIM 2021;8: doi:10.12890/2021_002266.

Conflicts of Interests: The Authors declare that there are no competing interests.

Acknowledgements: We thank Jane Charbonneau, DVM, from Edanz Group (https://en-author-services.edanzgroup.com/ac) for editing a draft of this manuscript.

This article is licensed under a Commons Attribution Non-Commercial 4.0 License

\section{ABSTRACT}

An enterolith in Crohn's disease is an uncommon but serious condition because it can cause intestinal obstruction. Endoscopic treatment to remove the enterolith is attempted first, but is sometimes difficult owing to poor accessibility of the endoscope. In such cases, surgical treatment is inevitable. We successfully overcame poor accessibility and removed an enterolith using double-balloon enteroscopy. We describe our method below and suggest several helpful techniques.

\section{LEARNING POINTS}

- Patients with Crohn's disease sometimes have a history of intestinal stricture, which can cause intestinal obstruction by enterolithrelated impaction.

- Endoscopic treatment is the first choice to remove an enterolith, but is sometimes difficult.

- We successfully removed an enterolith using double-balloon enteroscopy and employing several helpful techniques.

\section{KEYWORDS}

Crohn's disease, enterolith, intestinal obstruction, double-balloon enteroscopy

\section{CASE DESCRIPTION}

A woman in her 80s with Crohn's disease was referred to our hospital because of abdominal pain and nausea. As she had a history of intestinal stricture, computed tomography (CT) was performed to examine the intestine. A round object with oral-side jejunal extension was identified on CT (Fig. 1A), which was diagnosed as bowel obstruction caused by enterolith-related impaction. To remove the enterolith, a double-balloon enteroscope (DBE, EN-580T; Fujifilm, Tokyo, Japan) was inserted in the standard fashion as far as possible; however, the scope did not reach the enterolith. Contrast imaging revealed an intestinal stricture and a rectangular filling defect, which was considered to represent the enterolith. The filling defect was located at the distal side of the stricture and approximately $30 \mathrm{~cm}$ away from the tip of the DBE (Fig. 1B). To approach the enterolith, we included the following three additional procedures. First, we fully inflated the balloon, which was mounted on the tip of the scope, to occlude the intestine. Second, full suction was applied via the DBE to create negative pressure on the distal side of the balloon. Third, abdominal compression was performed to gently straighten the colonic flexure to assist DBE insertion while the balloon was being deflated (Fig. 2A,B). 


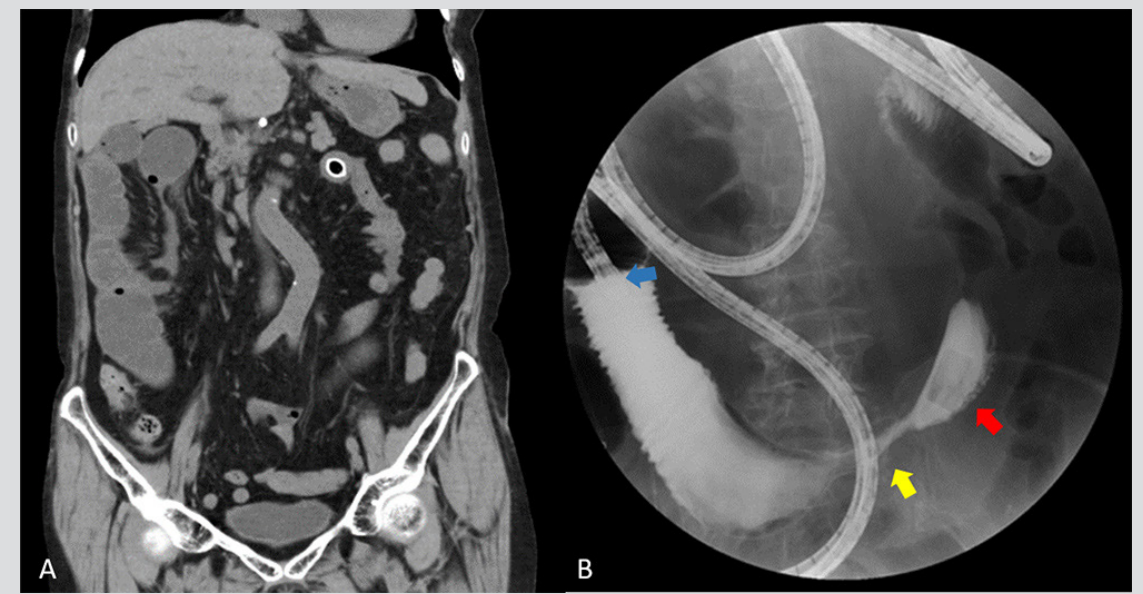

Figure 1 (A) Computed tomography (CT) images demonstrating an intraluminal small bowel enterolith with oral-side jejunal extension. (B) Double-balloon enteroscope (DBE) image showing a filling defect (red arrow) located at the distal side of the stricture (yellow arrow). At this stage, the tip of the DBE (blue arrow) was inserted as far as possible

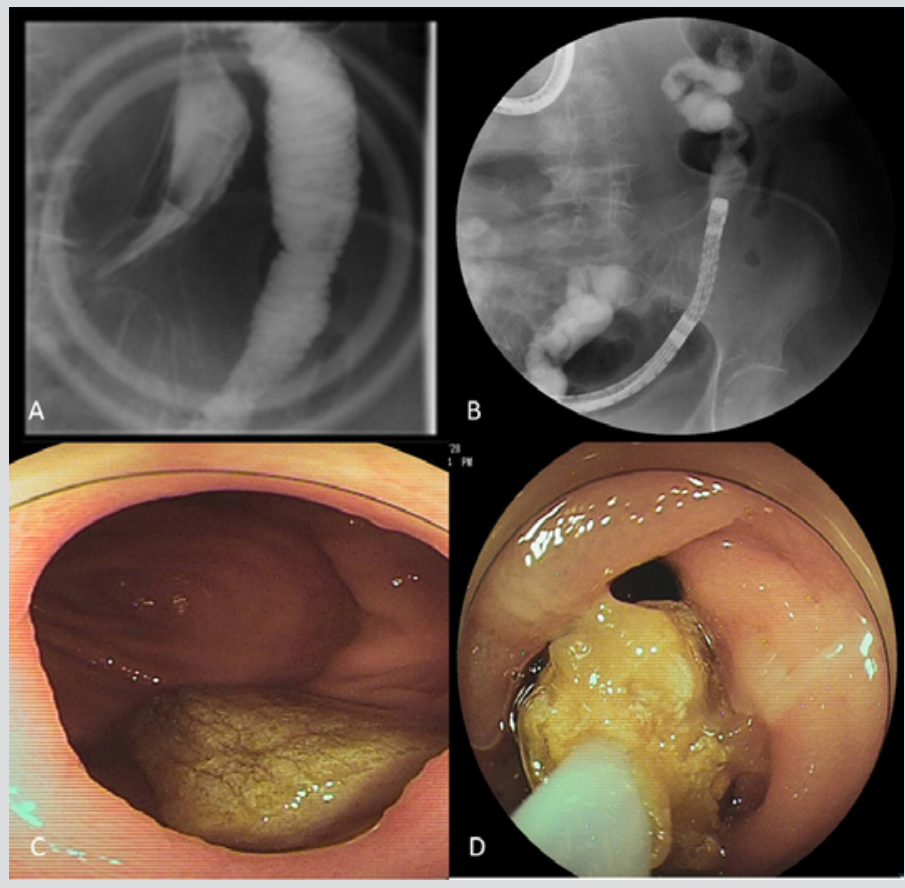

Figure 2 (A) The combination of suction and abdominal compression assisted doubleballoon enteroscope (DBE) insertion. (B) The tip of the DBE reached just in front of the enterolith. (C) Endoscopic findings of the enterolith. (D) The enterolith was captured using a polypectomy snare and removed

These procedures were performed in order, resulting in the tip of the DBE approaching the enterolith (Fig. 2B). The enterolith was extracted using a snare (Captivator II; Boston Scientific, Natick, MA, USA) without dilating the stricture (Fig. 2C,D), and the bowel obstruction was relieved. Chemical analysis indicated a false enterolith.

We successfully removed an enterolith using several helpful techniques. The clinical course after the procedure was uneventful and the patient was discharged several days later.

\section{DISCUSSION}

Patients with Crohn's disease can present with various intestinal complications including fistula, stricture and perforation ${ }^{[1,2]}$. Surgical treatment is sometimes essential for these conditions, but endoscopic treatment has recently also become possible following advances in endoscopic devices and techniques ${ }^{[2]}$. As in this case, intestinal obstruction caused by enterolith-related impaction can also be a serious problem for patients with Crohn's disease ${ }^{[3-5]}$. In this case, the patient had previously undergone endoscopic balloon dilation many times because of the stricture, and surgery had been considered to treat the stricture. However, in light of her age, medical and endoscopic treatments had been continued. 


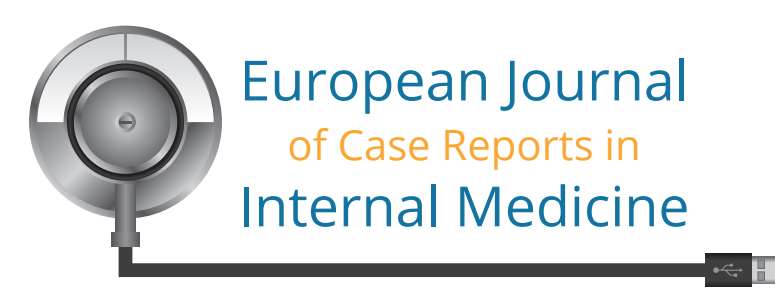

The accessibility of the DBE was poor because of several intestinal strictures, but we combined abdominal compression and negative pressure inside the intestine, resulting in approach to the enterolith and successful removal.

We herein have reported successful removed of an enterolith in a patient with Crohn's disease using a DBE and have suggested several helpful techniques.

\section{REFERENCES}

1. Steinhart AH, Girgrah N, McLeod RS. Reliability of a Crohn's disease clinical classification scheme based on disease behavior. Inflamm Bowel Dis 1998;4:228-234.

2. Bettenworth D, Bokemeyer A, Kou L, Lopez R, Bena JF, El Ouali S, et al. Systematic review with meta-analysis: efficacy of balloon-assisted enteroscopy for dilation of small bowel Crohn's disease strictures. Aliment Pharmacol Ther 2020;52:1104-1116.

3. Gurvits GE, Lan G. Enterolithiasis. World J Gastroenterol 2014;20:17819-17829.

4. Tewari A, Weiden J, Johnson JO. Small-bowel obstruction associated with Crohn's enterolith. Emerg Radiol 2013;20:341-344.

5. Muthukumarasamy G, Nairn ER, McMillan I. Enterolith and small bowel perforation in Crohn's disease. Inflamm Bowel Dis 2011;17:E126-127. 